Dipartimento di 
Dipartimento di Scienze Economiche

Università degli Studi di Cassino

Via S.Angelo Località Folcara, Cassino (FR)

Tel.+3907762994734 Email dipse@eco.unicas.it 


\title{
Scitovsky and the income-happiness paradox
}

\author{
Maurizio Pugno
}

December 8, 2011

\begin{abstract}
The recent debate on happiness in economics has revived interest in Scitovsky's 1976 book The Joyless Economy, which aims at explaining the income-happiness paradox, i.e. "why [American] unprecedented and fast-growing prosperity had left its beneficiaries unsatisfied." A dynamic economic model will distil Scitovsky's proposal, which has not yet been integrated into conventional economics. It will show that people's dissatisfaction may be due to their excess of demand for 'comfort', which requires consumption goods, and to their lack in pursuing 'creative activities', which instead essentially require leisure and a skill, called 'leisure skill', that people have failed to develop. Since comfort includes comparing consumption with that of others, Scitovsky also strengthened the conventional solution of the paradox.
\end{abstract}

J.E.L. classification: A12, D60, J24, Z10

Keywords: Scitovsky; income-happiness paradox; comfort; creative activities; leisure skill.

Address: Department of Economic Sciences and CreaM, University of Cassino, Campus Folcara, 03043 Cassino, Italy; m.pugno@unicas.it, tel.: +39 0776 2994702; fax: +3907762994834.

Acknowledgements: I wish to thank the participants at the Conference on "Policies for Happiness" (14-16 June 2007, Siena, Italy), and at the 5th National Storep Meeting (6-7 June 2008, Rome), who discussed a previous version of this paper, and in particular, M. Bianchi, P. Earl, V. Di Giovinazzo, and the whole CreaM group for their comments and encouragement. The financial support for this research provided by MIUR is gratefully acknowledged. 
"There are stimulating ideas aplenty in this volume. The challenge for the next generation of economists is to discover how to formalize these ideas and integrate them into the existing body of neoclassical thought. We can be confident that careful research along these lines yield high returns indeed"

(R.H.Frank. Foreword to The Joyless Economy, second edition, 1992, p.v)

\section{Introduction}

In his 1976 book The Joyless Economy, Tibor Scitovsky set out an innovative approach to interpreting the income-happiness paradox, as captured by the key question of "why [American] unprecedented and fast-growing prosperity had left its beneficiaries unsatisfied" (1992[1976], p.vi). Scitovsky was innovative, because he proposed to introduce in economics new psychological concepts, such as intrinsic motivations, comfort, creativity and leisure skill, thereby extending the explanatory power of the analysis.

Two years previously, Richard Easterlin had made evident the paradox by finding that the average of self-reported happiness in the US was almost unchanged over decades, despite economic growth, whereas richer people reported greater levels of happiness than poorer ones (Easterlin 1974). ${ }^{1}$ Scitovsky contributed to understanding the paradox by providing an analysis which is both innovative and able to strengthen the currently most widely accepted solution of the paradox (Clark et al. 2008).

Since the publication of The Joyless Economy, with the rapid development of economic research on happiness, Scitovsky has been cited many times, and by authoritative contributors in the field (Easterlin, 1995; Clark and Oswald, 1996; Frank, 1997; Layard, 2005; Kahneman et al., 2006; Frey, 2008). He has also been cited outside the economic field, especially by psychologists (Hoch and Loewenstein, 1991; Csikszentmihalyi, 1999; Diener et al., 1999; Sheldon and Lyubomirsky, 2006). The book was discussed and appreciated in the 1996 symposium of Critical Review by Amartya Sen and Albert Hirschman, among others, and it even had the honour of being classified as one of "The hundred most influential books since World War II" by the Times Literary Supplement on 6 October $1996 .^{2}$

However, Scitovsky's analysis of the "well-being of the individual person" (Scitovsky, 1986, p.ix) has not yet been fully investigated, and today it appears not be integrated into conventional economic theory. He has instead been defined as an "outlier" (Angner and Loewenstein, 2007), or a "questioning economist" (Bianchi, 2003). When the Easterlin paradox has been discussed,

\footnotetext{
${ }^{1}$ The existence of the Easterlin paradox has subsequently been both confirmed (Easterlin and Angelescu, 2009; Layard et al., 2009), and challenged (Stevenson and Wolfers, 2008), although a consensus seems to emerge if well-being is measured in its most emotional component (Kahneman and Deaton, 2010; Oswald, 2010).

${ }^{2}$ For an account of Scitovsky's intellectual life and contributions see Earl (1992), and Bianchi (2003). Scitovsky's book especially influenced consumer research (e.g. Bianchi 2002; Frank 1999; Earl and Potts 2004).
} 
Scitovsky has usually been mentioned and cited in regard to aspects of his book which are not the most central and innovative ones. ${ }^{3}$

The present paper proposes a model with which to capture the most innovative aspects of the analysis in Scitovsky's book and his other related works, and to show how it can be integrated into conventional economics. His contributions to happiness economics, and to the income-happiness paradox in particular, will thus emerge clearly.

Scitovsky's main argument is that people's dissatisfaction is due to their excess of demand for 'comfort', compared to demand for 'creative activities'. Comfort essentially requires consumption goods, and tends to form habits, or even harmful addictions. Creative activities are rather characterised by novelty, and require, in addition to consumption goods, both leisure and the skill to enjoy these activities. Such skill was called 'leisure skill' by Scitovsky, to underline when this skill is usually exercised, but he rather meant the more general skill to "organize our life" (1992[1976], p.269). He argued that people usually fail to develop this skill, so to underappreciate the creative activities.

Since Scitovsky's notion of comfort also included the social comfort of comparing one's own consumption with that of others, this analysis enriches and strengthens the most popular solution of the income-happiness paradox. According to this solution, comparing one's own consumption with that of others implies that individuals play a zero-sum game where nobody is better-off while consumption of all rises, but richer individuals neverthelss remain more satisfied than poorer ones. Scitovsky's analysis thus contributes to understanding why individuals are induced to compare their consumptions.

Encapsulating Scitovsky's thought in a model also helps clarify to what extent his analysis can be integrated into conventional economics. The main example is Scitovsky's argument that the primary motivation driving the creative activities is to enjoy them for their own sake, so that their effect on the formation of an individual's leisure skill can be regarded as an 'internality'. This internality interacts with the individual's attempt to select the most adequate creative activity, so to yield interesting but unconventional results: that the individual may follow a path of well-being development which is not optimal, and that there does not generally exist the case of optimal information such that the individual finds it convenient to cease learning to improve her/his well-being.

Scitovsky thus anticipated the use of results obtained in psychology which has become usual in 'behavioural economics' (see Camerer et al., 2004). He also anticipated specific results recently confirmed in psychology and other disciplines, such as the benefit of curiosity, as implied by creative activities, and the harm of boredom, as implied by the lack of creative activities. Therefore, Scitovsky's "hope to open a new field of enquiry" (1992[1976], p.288) may come to be fulfilled.

The paper is organised as follows: section 2 introduces the main new concepts and arguments of Scitovsky's analysis of well-being, and briefly reports some

\footnotetext{
${ }^{3}$ Scitovsky has been cited as representing the interpretation based on comparison consumption (Oswald 1997; Frank 1997), or on adaptation (Sheldon and Lyubomirsky 2006).
} 
supporting empirical evidence from the literature; section 3 formalises the core of this analysis into a model of consumer choice and preference dynamics, and then resolves the model; section 4 shows how the income-happiness paradox can be interpreted along Scitovskyian lines, and what policies are thus implied; the Conclusions end the paper.

\section{Scitovsky's main concepts and arguments}

The main concepts and arguments in Scitovsky's analysis on well-being refer to 'comfort', 'novelty', 'creative activities', and 'leisure skill'. Since these concepts and arguments are rather new, some brief explanations are necessary, so as to provide the basis for the model set out in the following section. Scitovsky's book draws on the empirical results of psychological literature of the 1950s and 1960s in order to ground its psychological concepts and arguments. More recent evidence will be thus mentioned at the end of this section so as to provide an update to this grounding.

'Comfort' and 'novelty' are two sources of satisfaction with two types of underlying motivations that Scitovsky regarded as "mutually exclusive alternatives" (S., 1992[1976], p.72, where S. henceforth denotes Scitovsky). ${ }^{4}$ The individual would aim at achieving comfort as a goal in order to prevent or relieve discomfort and pain. Income and consumption goods are the means to this end, while no special skill is required to appreciate and enjoy comfort. In fact, in this case individuals are completely informed about their skills, and on how to satisfy their preferences. Scitosvky claimed that consumer theory usually limits itself to considering only this case (S. 1992[1976], p.30).

Moreover, Scitosvky observed that the satisfaction obtained from comfort is rapidly reduced by two psychological mechanisms. First, the individual becomes habituated to comfort, "usually without full awareness" (S., 1992[1976], p.129), so that $\mathrm{s} /$ he needs greater amounts of it to be satisfied. If habit takes the strong form of addiction, the harmful effects on well-being are even greater $(\mathrm{S}$. 1992[1976], pp.124-131). Second, since comfort includes the social comfort of a good standing on the income scale, achieving a new level of comfort would be frustrated by others' achievements (S., 1992[1976], p.119; 1986[1985], pp.199200).

Alternatively, the individual searches for 'novelty' by pursuing 'creative activities' in order to enjoy the pleasure of both challenging her/his faculties and learning new things. Creative activities are thus intrinsically motivated because enjoyment is expected from performing the activity itself (S., 1986[1985] ${ }^{5}$. According to Scitovsky, this type of activity does not necessarily employ marketable products, as in the case of human relations (S. 1986[1972], p.61, see also

\footnotetext{
${ }^{4}$ Scitovsky also referred to the crowding-out of motivations, thus citing the motivational psychologist Edward Deci (S., 1986[1985], p.202), who has subsequently strengthened this claim with new evidence (Deci et al., 1999).

${ }^{5}$ The first reported date refers to the published collection of articles, while the date reported in square brackets refers to the original article.
} 
1986[1973], pp.17, 19), and it is typically performed during leisure time (e.g., S. 1992, pp.vii-viii). He thus underlined the importance of time in this experience of learning.

The typical creative activity is artistic work, both professional and nonprofessional (S., 1992[1976], pp.304-7). More generally, an activity is creative when "extending or deepening one's experience and knowledge of the world" yields enjoyment (S. 1986[1972], p.60).

However, the enjoyment expected from activities of this type is uncertain because the individual obviously does not know the content of the novelty. Moreover, but $\mathrm{s} /$ he does not even know whether $\mathrm{s} /$ he is prepared to enjoy it, or, in Scitovsky's terms, whether $\mathrm{s} /$ he is equipped with an adequate 'leisure skill'. If the degree of novelty of the activity chosen is scant, s/he experiences boredom; by contrast, if the degree of novelty is excessive with respect to the individual's leisure skill, s/he experiences anxiety (S. 1992[1976], pp.46-52, 59). ${ }^{6}$

Scitovsky also used interchangeably the term 'consumption skill', originally derived from the case of women's skill in managing the budget to satisfy very different consumption needs of the household (S., 1992[1976], p.73). He thus intended to show a case where information about the different options is especially far from complete. He also used the term 'life skill' (S. 1992, p.333), by which he meant the skill to take important choices on the basis of the experience of a few similar events (S. 1986[1979], pp.123-124). To show what makes an individual thus skilful, Scitovsky suggested the example of the arts, where appreciation comes from seeing "behind" the most apparent meaning (S. 1992[1976], p.56). Therefore, 'leisure skill' is ultimately the skill that induces the individual to take options which appear more uncertain but which s/he feels to be most rewarding. In support of this conclusion, Scitovsky referred to Keynes and Schumpeter when they talked about "animal spirits" and "urge to action" (S. 1986[1985], pp.189,198).

Scitovsky also held that the individual could acquire leisure skill at an early age through a healthy relationship with the caregivers, when creative activities should be the normal activities (S. 1992[1976], pp.49, 227; 1996, p.603; 2000 ), and then through education, when humanistic culture, as love for intellectual progress, should be of central place (S., 1992[1976], ch.11; 1986[1972], p.60). Leisure skill can be seen as a component of human capital because it cumulates; but it is a special component, because its future return is especially difficult to evaluate because of the uncertainty of novelty (S., 1992[1976], pp.123-4, 231). Leisure skill thus tends to cumulate as a side-effect during the individual's successful experience of creative activities, which are in fact motivated by immediate intrinsic reasons. When this experience is unsuccessful, e.g. because of inadequate caregiving and education, leisure skill may fail to cumulate. It may even deteriorate, thus inducing the individual to seek an immediate compensation - as substance addiction and other risky behaviour make evident (S., 1992[1976], pp.xi, 294; 2000, pp.49-50). Therefore, these side-effects of the

\footnotetext{
${ }^{6}$ Scitovsky represented this aspect with the Wundt curve, which is well-known in psychology (S. 1992[1976], p.35)
} 
leisure skills can be said to be positive or negative 'internalities'. ${ }^{7}$

Scitovsky's psychological concepts and arguments have received support from several recent studies in economics, psychology and other disciplines. The search for novelty and the pursuit of creative activities have been investigated in psychological research on curiosity, and on the need for cognition. In fact, "curiosity is defined as a positive emotional-motivational system associated with the recognition, pursuit, and self-regulation of novel and challenging opportunities" (Kashdan et al., 2004, p.291), while the need for cognition is the tendency to engage in effortful cognitive activity as an intrinsic motivation that can be developed through repeated or prolonged episodes of effortful problem solving (Cacioppo et al., 1996). It has been found that curious people or ones with a strong need for cognition usually report greater well-being (Kashdan and Steger, 2007), are more socially related (Kashdan and Roberts, 2006; Cacioppo et al., 1996), are healthier in old age (Silvia and Kashdan, 2009), and live longer (Swan and Carmelli, 1996). In particular, individuals with a high need for cognition tend to seek, acquire, and reflect in order to make sense of stimuli, relationships, and events in their world by drawing on both cognitions and affect, intuitions and images; whereas individuals low in need for cognition tend to ignore, avoid, or distort new information, and to pay close attention to social comparison cues (Cacioppo et al., 1996; Petty et al., 2009).

Further confirmation of Scitovsky's intuition is provided by a psychological study which observes that individuals feel and enjoy interest in a new activity when there is an adequate match between their appraisal of the objective novelty content and their appraisal of their coping potential to understand such novelty (Silvia and Kashdan 2009).

Scitovsky's unusual idea that uncertainty due to novelty may be pleasurable (S. 1992[1976], p.57) has also received some confirmation from recent research in neurosciences (Berns et al. 2006; Knutson and Cooper 2006).

Boredom was one of the main concerns in Scitovsky's later writings, but only recently has it been found to be positively correlated with psychological and physical health symptoms, like depression, compulsive behaviour, depression, anxiety, and even aggression (Sommers and Vodanovich 2000; Vodanovich et al. 1991; Dahlen et al. 2004). Indeed, it seems that boredom presages delinquent behaviour (Horvath and Zuckerman 1993) and substance abuse (Iso-Ahola and Crowley, 1991). An epidemiological study has even found that individuals with a great deal of boredom are more likely to die during follow-up than those not bored at all (Britton and Shipley 2010).

Scitovsky's bi-partition of motivations for comfort and for novelty is consistent with a body of empirical evidence in psychology which shows that extrinsic motivations, which are goal-oriented, cluster around preferences for "financial success, appearance, and social recognition", whereas intrinsic motivations, which are experience-oriented, cluster around preferences for "self-acceptance,

\footnotetext{
7 The original term used by Scitovsky for 'internality' is 'internal economies and diseconomies', which are generally defined as "internal side-effects that the production and/or the enjoyment of goods and services can have on the transacting parties", and that "many people ignore" (S. 1995[1993], pp.203-4).
} 
affiliation and community feeling." Similar extrinsic aspirations are associated with greater well-being more than are intrinsic aspirations (Kasser, 2002:129). A study in experimental psychology shows that extrinsic motivations are more attached to goal- or level-orientation, whereas intrinsic motivations are more attached to experience- or change-orientation (Hsee et al. 1991). Finally, an economic and cross-country study finds that, on controlling for income, individuals with higher levels of intrinsic motivation relative to extrinsic motivation also enjoy greater satisfaction with life (Salinas-Jiemenez et al. 2010).

Research in developmental psychology helps explain how individuals develop the specific skills required to appreciate exploration and novelty. For example, the 'attachment approach' maintains that the infant seeks to establish communication with the caregivers on whom $\mathrm{s} /$ he is entirely dependent for survival. If the caregivers are able to respond, 'secure' attachment arises, so that an infant feels secure in both exploring and relating with new others. If the caregivers are hyperprotective or control emotionality, 'insecure' attachment arises, so that the infant is disappointed in her/his need for relatedness, and refrain from exploration (Bowlby 1969; Ainsworth et al. 1978). This approach has been successfully tested on infants and children on many occasions and in various countries (Berscheid and Reis 1998). 'Attachment styles' seem also to characterise adolescents and young adults. Longitudinal studies reveal that early attachment strongly conditions later experience, even during adulthood (Sroufe et al., 2005; Waters et al., 2000).

Economic research has recently recognized that investing in children has very high returns (Cascio 2009; Heckman et al., 2009). In particular, Heckman et al. (2010) recognize that family environments and investments in children (mainly represented by parental education and maternal ability) causally affect the development of their skills of both cognitive and socio-emotional type, as evidenced by the outcomes of dropping out of school, incarceration, smoking, and teenage pregnancy. Economists usually stress the importance of economic conditions for adequate parenting, but their conclusions appear similar to those of psychologists (e.g. Sweeting and West 1995). In Heckman's (2008, p.16) words: "a substantial body of evidence suggests that a major determinant of child disadvantage is the quality of the nurturing environment rather than just financial resources available."

\section{The model}

The model will represent an individual whose choice set groups together all her/his activities into two options, i.e. 'comforts' and 'creative activities'. In the comfort option, the individual expects to achieve the maximum comfort from the basket of activities involved, as assumed in conventional consumer theory. However, s/he evaluates comfort not in absolute terms, but in comparison with that of others. Moreover, s/he may experience some adaptation over time.

For the option of creative activities, the model will specify four main characteristics: the essential requirement of leisure time, besides consumption goods, 
so to capture the experience aspect of this option; the consequent growth or deterioration of individual's leisure skill depending on how much the experience has been successful; the individual's attempts to adjust the degree of novelty (by selecting another creative activity) in order to make the experience as successful, i.e. adequate to his/her leisure skill; the possibility to enjoy creative activities with more novelties, the greater is his/her leisure skill.

The two options are greatly substitutable, thus capturing the underlying alternative motivations. The comfort option is especially preferred when the leisure skill is at especially low levels.

Therefore, the changes in an individual's well-being, as captured by the utility index, will be studied as the result of the interdependent and endogenous dynamics of the pleasure that $\mathrm{s} /$ he derives in pursuing creative activities, her $/$ his skill change, and her/his attempt to adjust novelty, vis-à-vis the comfort derived from the alternative option.

Subsection 3.1 sets out the assumptions, and subsection 3.2 resolves the model.

\subsection{Assumptions}

Let us assume that both options of the individual's choice set require some quantity of an undifferentiated consumption good, called $C$. In this way, it is clear that the difference between the two options does not lie in the characteristics of consumption goods.

Let us start with creative activities. These require a share of the individual's fixed (and unitary) available instantaneous time, called $A$, and the consumption good, thus denoted with $C_{a}$. Let us simplify matters by assuming that this option requires $A$ and $C_{a}$ in fixed proportions, which may change for exogenous reasons (as briefly discussed in section 4). Formally, this option is thus:

$$
\min \left(\gamma A_{t}, C_{a, t}\right) \quad \text { with } \quad 0<\gamma<\infty
$$

where $\gamma$ refers to the inputs proportion, and the subscript $t$ makes the attached variables time-varying.

This option appears as in (1) for its quantity dimension only, being measured in time and quantity of goods. In order to capture its quality dimension, as subjectively evaluated, let us consider the enjoyment $(u)$ that the individual derives from a unit of this option as a function of two variables: its degree of novelty, measured by the real number $\chi$, and the individual's skill in appreciating novelty, measured by the real number $S$. Formally:

$$
u_{t}=u\left(S_{t}, \chi_{t}\right) \quad \text { with } \quad 0<S_{t}<\infty, 0<\chi_{t}<\infty
$$

This function should fulfil three requirements. It should capture the fact that the individual experiences a reduced enjoyment if the degree of novelty is too low (boredom), or if it is too high (anxiety), so that the optimal experience is in between. In our terms, for every given level of $S$, there exists an optimal level of $\chi$, say $\chi^{M}$, such that $u$ has a global maximum labelled with $u^{M}$. The second 
requirement is that the more skilled is the individual, the greater the optimum level of the degree of novelty s/he can enjoy. Thirdly, function (2) should capture Scitovsky's idea that if the individual is especially low-skilled, and hence prone to boredom or anxiety, s/he finds this option highly substitutable with the comfort option. That is, $u$ greatly drops when $S$ is especially low.

To fulfil these requirements, function (2) may appear as in Figure 1, and it is assumed to display, without any loss of generality, the following properties. On the plane $(S, \chi)$ there exists the relationship:

$$
\chi_{t}^{M}=\chi^{M}\left(S_{t}\right) \quad \text { with } \chi_{S}^{M}>0, \chi_{S S}^{M} \leqslant 0, \chi^{M}(0)=0
$$

where the subscripts $S$ and $S S$ indicate first and second derivative respectively. The function $u^{M}$ can thus be defined by substituting (3) into (2):

$$
u^{M}\left(S_{t}\right)=u\left(S_{t}, \chi^{M}\left(S_{t}\right)\right)
$$

with the following properties:

$$
\begin{aligned}
& \lim _{S_{t} \rightarrow 0} u_{t}^{M}=0, \quad u_{S}^{M}>0, \quad \lim _{S_{t} \rightarrow \infty} u_{t}^{M}=\bar{u}^{M}<\infty \\
& u_{S S}^{M}>0 \text { for } S_{t}<s, \quad u_{S S}^{M}=0 \text { for } S_{t}=s, \quad u_{S S}^{M}<0 \text { for } S_{t}>s
\end{aligned}
$$

where $s \in] 0, \infty[$ is the threshold below which the individual finds this option especially substitutable with the comfort option. The properties in (5) and (6) thus depict a rising and S-shaped curve for $u^{M}$. The definition of $u^{M}$ also requires the following properties of function (2):

$$
\begin{array}{llll}
u_{\chi}>0 \text { and } u_{S}<0 & \text { if } & \chi_{t}<\chi_{t}^{M} \\
u_{\chi}<0 \text { and } u_{S}>0 \text { if } & \chi_{t}>\chi_{t}^{M}
\end{array}
$$

$<====$ Fig.1: A representation of the function $u_{t}=u\left(S_{t}, \chi_{t}\right)=====>$

Function (2) thus defines the range $\chi<\chi^{M}$ as the region where the individual will experience boredom, whereas in the range $\chi_{t}>\chi_{t}^{M}$, s/he will experience anxiety. ${ }^{8}$ Consistently with the Wundt curve as depicted by Scitovsky (1992[1976], Fig.1), $u$ may rapidly drop in the latter region for every given $S$, as $\chi$ rises, meaning that anxiety becomes panic when $\chi_{t}>>\chi_{t}^{M}$.

The alternative to the novelty option is the comfort option, which does not require leisure time but only the consumption good, thus denoted with $C_{b}$. This good is evaluated in comparison with that of others, say $c$.

The individual's utility function in the two options can thus be specified as:

$$
U_{t}=U\left[u_{t} \min \left(\gamma A_{t}, C_{a, t}\right),\left(C_{b, t} / c\right),-\eta Z_{b}\right]
$$

The main properties of this function are that the two arguments $\left(u_{t} \min (\cdot)\right)$ and $\left(C_{b} / c\right)$ are concave, essential, and can be easily, but not perfectly, substituted. Therefore, equation (9) reads thus: satisfaction from activities displaying

${ }^{8}$ Csikszentmihalyi (1990), on studying the relationship between our $S$ and $\chi$ to define the optimal experience, boredom and anxiety, uses a diagram (as here in Figure 2), which is the projection of function $(2)$ on the $(S, \chi)$-axes. 
novelty positively depends on the good match between the individual's skill, which is given to her/him at time $t$, and the novelty embodied in those activities, and on how much time and how many consumption goods s/he can devote to these activities. Satisfaction from comfort depends only on the consumption goods bought from the market. The arrival of novelty, if well-matched with individual's skill, thus works as a positive shock to the utility function. This case is similar to Schumpeter's case where the innovation works as a positive shock to the production function (Schumpeter, 1939, p.87).

The term $Z_{b}$ in equation (9) is an index for past consumption of $C_{b}$ (equation (16)), so that, at every point of time $t$, it is given. This term will capture the formation of habit or even addiction to comforts.

In order to buy the consumption good, the individual must work at the wage rate $w$ (measured in $C$ units), which is exogenously given. The budget constraint is thus:

$$
C_{a, t}+C_{b, t}=w L_{t} \quad 0<w<\infty
$$

where $L$ denotes the time share devoted to working.

The time constraint is set thus:

$$
A_{t}+L_{t}=1
$$

The dynamic part of the model includes an equation for describing the individual's skill change, and the conditions that describe her/his attempt to adjust the degree of novelty of the chosen activity, i.e. $\chi$. The formation of habit will be also specifically considered.

The equation for the skill dynamics is as follows:

$$
\dot{S}_{t}=\phi u_{t} \min \left(\gamma A_{t}, C_{a, t}\right)-\delta S_{t} \quad \text { with } 0<\phi<\infty, 0 \leqslant \delta<\infty
$$

where the dot denotes the derivative with respect to time, $\phi$ denotes the impact of experience on skill accumulation, and $\delta$ represents the autonomous rate of the decay of the skill, as suggested by Becker (1996) when considering the accumulation of human capital.

The conditions for adjusting the degree of novelty should avoid the assumption that the individual knows $\chi^{M}$ in advance, because s/he knows whether the degree of novelty is at the optimum only when it is revealed and matched with her/his skill. The individual only knows that $\mathrm{s} /$ he has experienced, although to a different extent, boredom, i.e. $\chi<\chi^{M}$, or anxiety, i.e. $\chi>\chi^{M}$, or, as a special case, neither of them, i.e. $\chi=\chi^{M}$. follows:

Her/his adjusting behaviour can thus be modelled in a very general way as

$$
\begin{aligned}
& \dot{\chi}=m\left(u^{M}-u_{t}\right) S_{t} \quad \text { if } \chi<\chi^{M} \\
& \dot{\chi}=0 \quad \text { if } \chi=\chi^{M} \\
& \dot{\chi}=-n\left(u^{M}-u_{t}\right) S_{t} \quad \text { if } \chi>\chi^{M}
\end{aligned}
$$


where $m$ and $n$ are, for simplicity, two positive and finite coefficients. The equations say that the individual searches for a higher or lower degree of novelty, the more severe has been his experience of boredom or anxiety respectively. Leisure skill appears in (13) and (15), although being unnecessary, in order to capture Scitovsky's emphasis on the fact that this skill helps in selecting the creative activity with the adequate degree of novelty.

Scitovsky also introduced habit formation and addiction to comfort, as in the case of drug addiction, by observing that in these cases the individual is firstly attracted, but then $\mathrm{s} /$ he is trapped with little satisfaction, or even with dissatisfaction, and increased quitting costs. Let us then assume that $Z_{b}$, which appears in the utility function (9), represents cumulated past consumption of $C_{b}$ according to the following standard equation:

$$
\dot{Z}_{b, t}=C_{b, t}-\varphi Z_{b, t} \quad \text { with } 0<\varphi<\infty .
$$

The model is closed by assuming that the individual maximises $U$ by choosing allocation of time between $A$ and $L$, subject to time and budget constraints, having considered her/his endowment of skill $(S)$, and by selecting the creative activity so to adjust its degree of novelty with respect to the previous experience $(\chi)$. Maximisation remains static, thus capturing Scitovsky's ideas that future return of creative activities is especially difficult to evaluate, and that people are conservative in predicting changes in their leisure skill. ${ }^{9}$

\subsection{The solution}

The individual maximises $U$ as given by function (9), and having considered the constraints, definitions, and properties (1)-(8), and (10)-(11). A solution for $A$ (denoted by a star) thus exists:

$$
0 \leqslant A_{t}^{*}=A[u, w, c, \gamma]<\frac{1}{1+\gamma / w}
$$

If $u \rightarrow 0$, then $A^{*} \rightarrow 0, C_{b}^{*} \rightarrow w$, and $U^{*}$ tends to the minimum for given $w, c, \gamma$. If $u \rightarrow \bar{u}^{M}$, and $\bar{u}^{M} \rightarrow \infty$, then $A^{*} \rightarrow 1 /(1+\gamma / w), C_{b}^{*} \rightarrow 0$, and $U^{*}$ tends to the maximum. Therefore, $\frac{\partial A^{*}}{\partial u}>0$, being $u$ and $A^{*}$ monotonically related.

If $A^{*}$ is sufficiently close to its maximum, then $\frac{\partial A^{*}}{\partial w}>0$ is warranted. For any admissible level of $A^{*}$, then $\frac{\partial A^{*}}{\partial w}>0$ if $\gamma$ is sufficiently great, since $1 / \gamma$ weights the $C_{a}$-component of the creative activities, which is affected by $w$. However, $\frac{\partial A^{*}}{\partial w}<0$ if $\gamma$ is sufficiently small.

The level of $u$ depends on $S$ and $\chi$, which are given at a given time, so that the dynamic of $u$ depends on the dynamics of $S$ and of $\chi$. In order to study

\footnotetext{
${ }^{9}$ Scitovsky thus refer to people, who "were gradually lured into a new way of life by their love of comfort, unaware at first of the costs involved and finding themselves fully accustomed to their new ways by time they realize the extent of the loss of pleasure suffered." (S. 1992[1976], p.73). More recently, behavioural economics has recognised that individuals systematically fail in predicting their own future utility changes (Loewenstein et al., 2003).
} 
the dynamics of $S$, let us plug $A^{*}$ into the accumulation function (12), thus obtaining:

$$
\dot{S}_{t}=\phi u\left(S_{t}, \chi_{t}\right) \gamma A\left[u\left(S_{t}, \chi_{t}\right), w, c, \gamma\right]-\delta S_{t}
$$

Let us then study the isocline $\dot{S}=0$ from (18) on the phase plane in the $(S, \chi)$-axes, and, at first, the portion of the isocline that lies in the region $\chi<\chi^{M}$. The implicit derivative theorem yields that $\frac{\partial \chi}{\partial S}>0$ because of (7), so that the isocline is rising. If $\chi \rightarrow \chi^{M}$, then the isocline tends to intersect $\chi^{M}$. In fact, the intersections of the isocline with $\chi^{M}$ can be found by substituting $\chi$ with $\chi^{M}(S)$ in (18), so that:

$$
\phi u\left(S_{t}, \chi^{M}\left(S_{t}\right)\right) \gamma A\left[u\left(S_{t}, \chi^{M}\left(S_{t}\right)\right), w, c, \gamma\right]=\delta S_{t}
$$

Both the 1.h.s. and the r.h.s of (19) are rising in $S$ by starting from the neighbourhood of zero, but the properties of $u^{M}$ in (5)-(6) guarantee that, apart from the trivial one, which is a limiting case, two intersections exist if $\delta$ is neither sufficiently low nor sufficiently high. If $\delta$ is sufficiently low, then one intersection exists. If $\delta$ is sufficiently high no intersection exists.

Let us then study the portion of the isocline $\dot{S}=0$ in the region $\chi>\chi^{M}$. The implicit derivative theorem again yields that $\frac{\partial \chi}{\partial S}>0$ because of (8), so that the isocline is rising again. If $\chi \rightarrow \chi^{M}$, then the isocline tends to have the same intersections as in the previous case.

Note that the term $\phi u\left(S_{t}, \chi_{t}\right) \gamma A\left[u\left(S_{t}, \chi_{t}\right), w, c, \gamma\right]$ exhibits very convex isoquants of $u$ on the $(S, \chi)$-axes, so that the two arms of the isoquant start from the same point lying on $\chi^{M}$, and both rise, although in the two opposite regions $\chi<\chi^{M}$ and $\chi>\chi^{M}$ respectively. Therefore, if $\delta$ is neither sufficiently low nor sufficiently high, the two portions of the isocline $\dot{S}=0$ scale up the isoquants by starting from the left intersection with $\chi^{M}(S)$, and pointing to the right towards the other intersection with $\chi^{M}(S)$ although lying in the two respective regions. The isocline $\dot{S}=0$ is thus almond-shaped, as in Figure 2. If $\delta$ were sufficiently low, then the first intersection would coincide, with the origin, at the limit. If $\delta$ were sufficiently high, then no isocline $\dot{S}=0$ would exist other than the limiting case of the origin.

$<====$ Fig. 2 : Phase-plane in the $(S, \chi)$-axes $====>$

Note also that $\dot{S} \rightarrow 0$ for $S \rightarrow 0$.

For any given $\chi\left(<\chi^{M}\right)$, then $\frac{\partial}{\partial S} \dot{S}<0$ in (18), so that the isocline $\dot{S}=0$ in this region describes a locus of attraction. Hence, the trajectories on the phase plane point rightwards if they lie on the left of this portion of the isocline $\dot{S}=0$; the trajectories point leftwards if they lie on the right of the same isocline. These dynamics of $S$ obviously cease when $\dot{S}=0$.

For any given $\chi\left(>\chi^{M}\right)$, then $\frac{\partial}{\partial S} \dot{S}>0$ in (18) if the $u$-function is sufficiently steep. Hence, the trajectories point towards the vertical axis if they lie on the left of this other portion of the isocline $\dot{S}=0$; the trajectories point rightwards if they lie on the right of the same isocline.

Since function (18) is continuous, the trajectories at $\chi^{M}$ maintain the same direction that they have in the horizontal neighbourhoods of $\chi^{M}$. 
Since the vertical axis is an attractor line, it also attracts all the trajectories not previously defined in both regions.

The dynamic of $\chi$ is rather simple, since the properties in (13)-(15), and the properties of the $u$-function (2) directly yield two conclusions: that the isocline $\dot{\chi}=0$ lies on the curve $\chi=\chi^{M}(S)$ of the phase plane, and that this isocline is an attractor line of $\chi$.

The model thus yields three equilibria: the trivial one, like $E_{1}$ in Figure 2, which is a limiting case, and the two intersections between the isoclines $\dot{S}=0$ and $\dot{\chi}=0$, like $E_{2}$ and $E_{3}$. The basin of attraction of the trivial stable point includes the regions where $S$ is very low for any $\chi$, and where $S$ is not very low, but $\chi$ is either very low or very great. All trajectories departing from the starting point outside these regions eventually approach the greatest intersection, i.e. $E_{3}$. Hence, only the $E_{1}$ - and $E_{3}$-types of equilibria are dynamically stable. The trajectories that tend to the trivial point represent the case where time tends to be entirely allocated for consuming $C_{b}$, so that $U^{*}$ would be at the minimum. At the other stable equilibrium point $\left(E_{3}\right)$, which is thus Pareto-superior, a proportion of time is also devoted to $A$ and to $C_{a}$. The smaller $\delta$ is, the further the $E_{3}$-type of equilibrium is from the trivial point, the greater the proportion of time allocated to $A$, and the greater is $U^{*}$.

These conclusions are not qualitatively altered by also taking into account the formation of habit and addiction according to equation (16). In steadystate (16) becomes $Z_{b}=C_{b}^{*} / \varphi$, so that satisfaction from repeatedly consuming $C_{b}$ diminishes, because the positive contribution of $C_{b}$ has been eroded by the negative contribution of $Z_{b}$ in equation (9) at the speed given by $\varphi$. The net contribution of $C_{b}$ may be even zero if $\eta$ were sufficiently great, thus representing the case of complete adaptation. The case of addiction would even suggest a negative net contribution of $C_{b}$. Utility $U^{*}$ is consequently affected in a negative way. If at some point of time $C_{b}^{*}$ increased because of some shocks in the parameters, e.g. $w$, the benefit would be temporary, because $Z_{b}$ would grow according to equation (16). Quitting from this consumption would make things even worse, since the cost of quitting, in terms of $U$, rises insofar as $Z_{b}$ grows. In the trajectory pointing to $E_{1}, U^{*}$ would diminish at greater rates in the case of habit or addiction. In the trajectory pointing to $E_{3}, U^{*}$ would decelerate.

A final interesting conclusion regards the lack of maximisation of $U$ over time. Not only the trajectories do not necessarily point to the $E_{3}$-type of equilibrium, which is the Pareto-superior one. But at any given moment of time, $U^{*}$ could be higher if $\chi$ were equal to $\chi^{M}$. Even if the trajectory approached $\chi^{M}$, after having reduced $\chi$ so that at $\chi=\chi^{M}$, the trajectory would not stop there, because the individual's skill would generally increase, and the existing degree of novelty would become too low. One may eventually approach $E_{3}$, but this case is not warranted because individual's life is finite. The equilibrium like $E_{3}$ may be even not exist because $\delta$ may be sufficiently low. Therefore, the individual, even in favorable conditions, generally appears in search to improve $U^{*}$. 


\section{Solving the income-happiness paradox}

In his later writings, Scitovsky emphasised one of the most dramatic aspect of the US, i.e. the diffusion of self-destructive and anti-social behaviours, such as drug addiction and violence (1992[1976], p.294). He then argued that this tendency "may be explained by the inadequate parenting of children" (S., 1996, p.601), and more precisely, that "boredom [...] is the consequence of children's inadequate parenting and students' insufficient schooling in peaceful leisure activities" (S., 2000, p.51).

In terms of the model suggested, these statements can be captured by the case of individuals who, although being born with a normal endowment of skill, say $S_{2}<S_{t=0}<S_{3}$ in Figure 2, experience a degree of novelty in their activities during infancy, say $\chi_{t=0}$, which was very low with respect to $\chi^{M}\left(S_{t=0}\right)$. In fact, $\chi_{t=0}$ is not chosen by the child but is usually fixed by parenting and preprimary school educators. In this case, the point $\left(S_{t=0}, \chi_{t=0}\right)$ lies in the basin of attraction of $E_{1}$ in Fig.1, and it represents the case of severe boredom. This appears to be relieved by consuming comfort as substitute goods. However, the benefit is temporary, because the low level of creative activities does not allow individuals' skill to accumulate, so that boredom arises again, and it may even become anxiety. In Figure 2 the trajectory is pointing to the trivial equilibrium, so that $C_{b}$ especially cumulates with negative effects on $U^{*}$ through $Z_{b}$ in equation (9).

In his book, Scitovsky mainly referred to boredom in the affluent society, where the lack of creative activities is typically revealed by the time spent watching television, with the ensuing regret for this behaviour (S., 1992[1976], pp.232-235). This case may be captured by individuals who start with a mildly lower level of $\chi_{t=0}$ with respect to $\chi^{M}\left(S_{t=0}\right)$, so that they experience boredom, but they also attempt to remedy it by looking for novelty. This case lies in the basin of attraction of $E_{3}$, but the dynamic is relatively slow, which is relevant since individuals' lives are finite.

The model predicts that behaviours of the type of drug addiction and heavy TV viewing may become prevalent in the case of economic growth, as captured by the exogenous rise of $w$. Indeed, the effects of the rise in $w$ is to increase $C_{b}^{*}$ relatively to $C_{a}^{*}$, and to increase $L^{*}$ and reduce $A^{*}$, if creative activities are little intensive of consumption goods, i.e. if $\gamma$ is sufficiently low. Consequently, individuals experience a reduced accumulation of leisure skill, so that they tend to approach the $E_{3}$-type of equilibrium more slowly, or approach the $E_{1}$-type of equilibrium more quickly, or turn from the former tendency to the latter. In terms of Figure 2, the basin of attraction of the $E_{3}$ diminishes since the almond-like shape of the isocline $\dot{S}=0$ shrinks. Therefore, with the rise of $w$, every generation of individuals experiences less and less accumulation of $S$, or even experiences decumulation. The effects of $w$ and $S$ on $U^{*}$ are opposite in sign, so that $U^{*}$ rises less than $w$, and it may even decrease.

This contribution to explaining the income-happiness paradox enriches and strengthens the most popular explanation, which is based on comparing consumption (or income) (Clark et al. 2008). Since in the case of economic growth 
also others' consumption would rise, then both $w$ and $c$ rise in the model. But the rise of $c$ makes the alternative option, i.e. the creative activities, more appealing, thus counteracting the effects due to the rise of $w$. Consequently, both $A^{*}$ and the basin of attraction of $E_{3}$ may diminish at lower rates. If $E_{3}$ disappeared and all trajectories eventually pointed to $E_{1}$, then $U^{*}$ would tend to remain constant, despite the rise of $w$.

Therefore, insofar as creative activities are pursued, the negative externality due to comparison consumption does not erode the beneficial effect of economic growth on well-being. In the limiting case where no creative activities are pursued, economic growth does not give any benefit to well-being, which is completely eroded by the comparison consumption effect. The standard interpretation based on comparing consumption assumes no alternative option to this choice, so that individuals' frustration in seeing their well-being eroded by comparisons cannot be escaped. The Scitovksyian interpretation helps understand why the alternative option becomes increasingly precluded.

The model is also able to give account of the second most popular interpretation of the income-happiness paradox, i.e. the one based on 'adaptation', which is a negative internality due to habituation to past consumption (Clark et al., 2008). Adaptation has been already considered by the dynamics triggered by equation (16), and by the term $Z_{b}$ in equation (9). Complete offsetting adaptation would emerge in the limiting case where demand were completely shifted towards $C_{b}^{*}, \eta$ were sufficiently great (and $c$ were constant), so that $U^{*}$ may remain constant, despite the rise of $w$.

Growth in $w$ could be endogenised if human capital for production purposes were introduced into the model, i.e. if a third share in the allocation of time, besides $A$ and $L$, were used in order to accumulate human capital, thus increasing $w$ in future periods. This time investment in human capital would be more at the expense of $A^{*}$ than of $L^{*}$, thus representing Scitovsky's argument that the future return on productive human capital is more certain than that on leisure skill.

In conclusion, the model is able to contribute substantially to solving the income-happiness paradox because it offers a new explanation as to why happiness may lag behind income over time, and because it strengthens the existing explanations. The fact that the erosion of happiness by comparison and adaptation may be partial can thus be better understood. Moreover, also the explanation of harmful addiction is new, because it is based on both habituation and the rise of the opportunity costs due to failures in enjoying creative activities, thus departing from the Beckerian explanation of the rising marginal utility of addictive consumption.

Positive externalities of leisure skill towards social creative activities are not considered by the model. However, if the individual taken for reference is representative of the community, then a social multiplier would apply in the case of these externalities.

The policy options implied by Scitovsky's analysis are rather new, at least in regard to priorities among economic policies. Scitovsky recommended, in fact, that especial attention to be paid to adequate parenting (S., 2000), and to 
humanistic education (S., 1992[1976], pp.224-5, 229). In terms of the model, adequate parenting means finding a level of $\chi_{t=0}$ as close as possible to $\chi^{M}\left(S_{t=0}\right)$. In this case, the trajectory would start within the basin of attraction of $E_{3}$, thus representing the benefits of adequate parenting as briefly discussed and documented in section 2 . The high costs of remediation of inadequate parenting at later ages may be represented by the contrast with the trajectory, which had already achieved the basin of attraction of $E_{1}$.

Scitovsky's second main recommendation regards humanistic education for the formation of leisure skill at school, in contrast to the education restricted to market-oriented specialisation (see also Nussbaum, 2010). More generally, cultural policy should provide more opportunities and favourable contexts so as to make intrinsically motivated activities more effective in acquiring novelties. In terms of the model, this type of intervention would increase $\phi$, which would enlarge the basin of attraction of the $E_{3}$.

Scitovsky gave the arts a special place in humanistic education. Any policy favouring the skill to appreciate the arts would alleviate the problem of financing them, also known as Baumol's 'cost disease' problem.

Finally, as the title of Scitovsky's (1986, ch.14) article How to Bring Joy into Economics suggests, optimistic scenarios arise if once-for-all policies are effective in encouraging people to use consumption goods for creative purposes $\left(C_{a}\right)$, rather than for comparison $\left(C_{b}\right)$, i.e. to increase $\gamma$. In this case the rise in $w$ may have a prevailing income effect on demand for $C_{a}$, so that economic growth may favour creative activities. Moreover, if the formation of skill in appreciating novelty affects the skill for innovation, as some results in psychology suggest (Collins and Amabile 1998; Isen 2000), this would help economic growth to become endogenous (Pugno, 2006).

\section{Conclusions}

When Scitovsky delivered lectures on his book, he found "unanimous hostility to [his] ideas" (S., 1976, p.xv). Orthodox economists probably disliked the subjectivist and psychological bases of his approach, while institutionalist economists probably disliked his liberal thought (S., 1992[1976], p.19). Even in our times, Scitovsky's proposal has not yet been integrated into conventional economics, and, in the case of happiness economics, only his analysis on comparative consumption seems to be recognised. This paper has sought to re-read Scitovsky's proposal from a conventional perspective, and to re-establish his contribution, by relying on the recent attention in economic research to psychology results.

Interesting conclusions can thus be drawn. First, an original contribution for understanding the income-happiness paradox emerges. Secondly, both popular interpretations of the paradox, i.e. the ones based on relative income and adaptation, thus become enriched and strengthened. Thirdly, new policy options may arise.

Scitovsky opened a new line of inquiry, and this paper is a theoretical contribution in this direction. His interpretation of the income-happiness paradox 
still awaits comprehensive empirical investigation, but encouraging results have recently emerged. For example, the excessive demand for comfort at the expense of social relationships, with negative effects on well-being, seems confirmed in the case of over-eating, and hence obesity, where self-control problems appear to play a role (Stutzer, 2007; Downs et al., 2009; Katsaiti, 2010). Similar results emerge in the case of excessive television viewing (Frey et al. 2007; Benesch et al. 2010; Bruni and Stanca 2008; Corneo 2005). Another example regards the dynamics of the social component of creative activities, as proxied by general trust in people. This indicator exhibits for the US during recent decades a declining trend (Robinson and Jackson, 2001) which appears to account for, together with relative income, the stagnant level of average self-reported happiness (Bartolini et al., 2011).

\section{References}

Ainsworth, M.D.S., Blehar, M.C., Waters, E., Wall, S., 1978. Patterns of Attachments. Erlbaum, Hillsdale (NJ).

Angner, E., Loewenstein, G., 2007. Behavioral economics, in Maeki, U. (ed.) Philosophy of Economics. Elsevier, Amsterdam (forthcoming)

Bartolini, S., Bilancini, E., Pugno, M., 2011. Did the decline in social connections depress Americans' happiness?. Social Indicators Research (forthcoming).

Becker, G.S., 1996. Preferences and values. In Becker G.S. (Ed.) Accounting for tastes, Harvard University Press, Harvard, 3-23.

Benesch, C., Frey, B.S., Stutzer, A., 2010. TV Channels, self control and happiness. B.E. Journal of Economic Analysis \& Policy 10(1), Article 86.

Berns, G.S., McClure, S.M., Pagnoni, G., Montague, P.R., 2001. Predictability modulates human brain response to reward. Journal of Neuroscience 21(8), 2793-8.

Berscheid, E., Reis, H.T., 1998. Attraction and close relationships. In Gilbert, D.T., Fiske, S.T. (Eds.) Handbook of Social Psychology. Vol. 2 (4th ed.). McGraw-Hill, New York, 193-281.

Bianchi, M., 2002. Novelty, preferences, and fashion, Journal of Economic Behavior and Organization, 47, 1-18.

Bianchi, M., 2003. A questioning economist: Tibor Scitovsky's attempt to bring joy into economics. Journal of Economic Psychology 24, 1-18.

Bowlby, J., 1969. Attachment and Loss. Basic Books, New York.

Britton A., Shipley, M.J. 2010. Bored to death?. International Journal of Epidemiology 39, 370-371.

Bruni, L., Stanca, L., 2008. Watching alone. Journal of Economic Behavoir \& Organization 65(3-4), 506-528.

Camerer, C.F., Loewenstein, G., Rabin, M., 2004. (Eds) Advances in Behavioral Economics. Princeton University Press, Princeton.

Cacioppo, J.T., Petty, R.E., Feinstein, J.A., Jarvis, W.B.G., 1996. Dispositional differences in cognitive motivation. Psychological Bulletin, 119, 197-253. 
Cascio, E.U., 2009. Do investments in universal early education pay off?. NBER wp 14951.

Clark, A.E., Oswald, A.J., 1996. Satisfaction and comparison income. Journal of Public Economics 61(3), 359-381.

Clark, A.E., Frijters, P., Shields, M., 2008. Relative income, happiness and utility. Journal of Economic Literature 46(1), 95-144.

Collins, M.A., Amabile, T.M., 1998. Motivation and creativity, in R.J. Sternberg (ed.) Handbook of Creativity. Cambridge University Press, Cambridge, pp. $297-312$.

Corneo, G., 2005. Work and television. European Journal of Political Economy 21, 99-113.

Cunha, F., Heckman, J.J., 2009. The economics and psychology of inequality and human development, NBER wp 14695.

Cunha, F., Heckman, J.J., Lochner, L.J., Masterov, D.V., 2006. Interpreting the evidence on life cycle skill formation. In E.A. Hanusheck, F. Welch (Eds). Handbook of the Economics of Education, North-Holland, Amsterdam, pp.697804 .

Csikszentmihalyi, M., 1990. Flow. Harper and Row, New York.

Csikszentmihalyi, M., 1999. If we are so rich, why aren't we happy? American Psychologist, Oct., 821-827.

Dahlen, E.R., Ryanj, C.M., Ragan, K., Kuhlman, M.M., 2004. Boredom proneness in anger and aggression. Personality and Individual Differences 37(8), $1615-1627$.

Deci, E.L., Koestner, R., Ryan, R.M., 1999. A meta-analytic review of experiments examining the effects of extrinsic rewards on intrinsic motivation. Psychological Bulletin 125, 627-668.

Diener, E., Suh, E.M., Lucas, R.E., Smith, H.I., 1999. Subjective well-being: three decade of progress. Psychological Bulletin 125(2), 276-302.

Downs, J. S., Loewenstein, G., Wisdom, J., 2009. Strategies for promoting healthier food choices. American Economic Review: P\&P, 99(2), 1-10.

Earl, P.E., 1992. 'Tibor Scitovsky'. In Samuels, W.J. (Ed) New Horizons in Economic Thought, Edward Elgar, Aldershot, 265-93.

Earl, P.E., Potts, J., 2004. The market for preferences, Cambridge Journal of Economics, 28(4), 619-633.

Easterlin, R.A., 1974. Does economic growth improve the human lot? In David P.A., Melvin, W.R. (Eds.), Nations and Households in Economic Growth. New York, Academic Press, 89-125.

Easterlin, R.A., 1995. Will raising the incomes of all increase the happiness of all? Journal of Economic Behavior \& Organization 27(1), 35-47.

Easterlin, R.A., Angelescu, L., 2009. Happiness and growth the world over. IZA dp 4060.

Frank, R.H., 1997. The frame of reference as a public good. Economic Journal 107, 1832-47.

Frank, R.H., 1999. Luxury Fever. New York: The Free Press.

Frey, B.S., 2008. Happiness, Cambridge, MIT Press. 
Frey, B.S., Benesch, C., Stutzer, A., 2007. Does watching TV make us happy?, Journal of Economic Psychology, 28(3), 283-313.

Heckman, J.J., 2008. School, skills, and synapses. NBER wp 14064.

Heckman, J.J., Moon, S.H., Pinto, R., Savelyev, P.A., Yavitz, A., 2009. The rate of return to the high/scope Perry Preschool Program, IZA dp 4533.

Heckman, J.J., Malofeeva, L., Pinto, R., Savelyev, P., 2010. Understanding the mechanisms through which an influential childhood program boosted adult outcomes, University of Chicago.

Hoch, S.J,. Loewenstein, G.F., 1991. Time-inconsistent preferences and consumer self-control, Journal of Consumer Research, 17(4), 492-507.

Horvath, P., Zuckerman, M., 1993. Sensation seeking, risk appraisal and risky behaviour. Personality and Individual Differences 14, 41-52.

Hsee, C.K., Abelsone, R.T., Salovey, P., 1991. The relative weighting position and velocity in satisfaction. Psychological Science 2(4), 263-6.

Isen, A.M., 2000. Positive affect and decision making. In Lewis, M., HavilandJones, J.M. (Eds) Handbook of Emotions. Guilford, 2nd ed., New York, 417-35.

Iso-Ahola, S.E., Crowley, E.D., 1991. Adolescent substance abuse and leisure boredom. Journal of Leisure Research 23(3), 260-71.

Kahneman, D., Deaton, A., 2010. High income improves evaluation of life but not emotional well-being, PNAS Early Edition, 1-5. Available on 12/3/2011 at:

http://www.pnas.org/content/early/2010/08/27/1011492107.full.pdf+html

Kahneman, D., Krueger, A.B., Schkade, D., Schwartz, H., Stone, A.A., 2006. Would you be happier if you were richer?. Science 312, 1908-10.

Kashdan, T.B., Roberts, J.E., 2006. Affective outcomes in superficial and intimate interactions. Journal of Research in Personality 40, 140-167.

Kashdan, T.B., Rose, P., Fincham, F.D., 2004. Curiosity and exploration. Journal of Personality Assessment 82(3), 291-305.

Kashdan, T.B., Steger, M.F., 2007. Curiosity and pathways to well-being and meaning of life. Motivation and Emotion 31, 159-73.

Kasser, T., 2002. The High Price of Materialism. MIT Press, Cambridge.

Katsaiti, M.-S., 2010. Obesity and Happiness. SOEP paper 270, DIW Berlin.

Keely, L.C., 2005. Why isn't growth making us happier?, Journal of Economic Behavior \& Organization 57, 333-355.

Knutson, B., Cooper, J.C., 2006. The lure of the unknown, Neuron, 07, 280-282

Layard, R., 2005. Happiness. Penguin Press, New York.

Layard, R., Mayraz, G., Nickell, S., 2009. Does relative income matter? CEP Discussion Paper 918, March.

Loewenstein, G., O'Donoghue, T., Rabin, M., 2003. Projection bias in predicting future utility. Quarterly Journal of Economics 118(4), 1209-48.

Nussbaum, M., 2010. Not for Profit. Princeton University Press, Princeton.

Oswald, A.J., 1997. Happiness and economic performance. Economic Journal 107, 1815-31. 
Oswald, A.J., 2010. Emotional prosperity and the Stiglitz Commission. British Journal of Industrial Relations 48, 651-669.

Petty, R.E., Brinol, P., Loersch, C., McCaslin, M.J., 2009. Need for cognition, in M.R. Leary, R.H. Hoyle (eds) Handbook of Individual Differences in Social Behavior, Guilford, New York, 318-29.

Pugno, M., 2006. The service paradox and endogenous economic growth. Structural Change and Economic Dynamics 17, 99-115.

Robinson, R.V., Jackson, E.F., 2001. Is trust in others declining in America?, Social Science Research 30, 117-145.

Salinas-Jieménez, M., Artés, J., Salinas-Jieménez, J., 2010. Income, motivation, and satisfaction with life. Journal of Happiness Studies, 11, 779-93.

Schumpeter, J.A., 1939. Business Cycles. McGraw Hill, London.

Scitovsky, T., 1986. Human Desires and Economic Satisfaction. New York University Press, New York.

Scitovsky, T., 1992. The Joyless Economy. Oxford University Press, Oxford. Revised edition, [First edition 1976].

Scitovsky, T., 1995. Economic Theory and Reality. Elgar, Aldershot.

Scitovsky, T., 1996. My own criticism of the Joyless Economy. Critical Review 10(4), 595-606.

Scitovsky, T., 2000. The wages of boredom. New Perspectives Quarterly, Spring, 45-51.

Sheldon, K.M., Lyubomirsky, S., 2006. Achieving sustainable gains in happiness. Journal of Happiness Studies 7(1), 55-86.

Silvia, P.J., Kashdan, T.B., 2009. Interesting things and curious people. Social and Personality Psychology Compass 3/5, 785-797.

Sommers, J., Vodanovich, S.J., 2000. Boredom proneness. Journal of Clinical Psychology 56, 149-155.

Sroufe, L. A., Egeland, B., Carlson, E., Collins, W.A., 2005. The Development of the Person. Guilford, New York.

Stevenson, B., Wolfers, J., 2008. Economic growth and happiness. Brookings Papers on Economic Activity May, 1-87.

Stutzer, A., 2007. Limited self-control, obesity and the loss of happiness. IZA dp 2925.

Swan G.E., Carmelli D., 1996. Curiosity and mortality in aging adults. Psychology and Aging 11(3), 449-53.

Sweeting H, West P. (1995). Family life and health in adolescence, Social Science and Medicine 40(2), 163-75.

Vodanovich, S. J., Verner, K., Gilbride, T., 1991. The relationship between boredom proneness and positive and negative affect. Psychological Reports 69, 1139-1146.

Waters, E., Hamilton, C.E., Weinfield, N.S., 2000. The stability of attachment security from infancy to adolescence and early adulthood, Child Development 71, 703-6. 


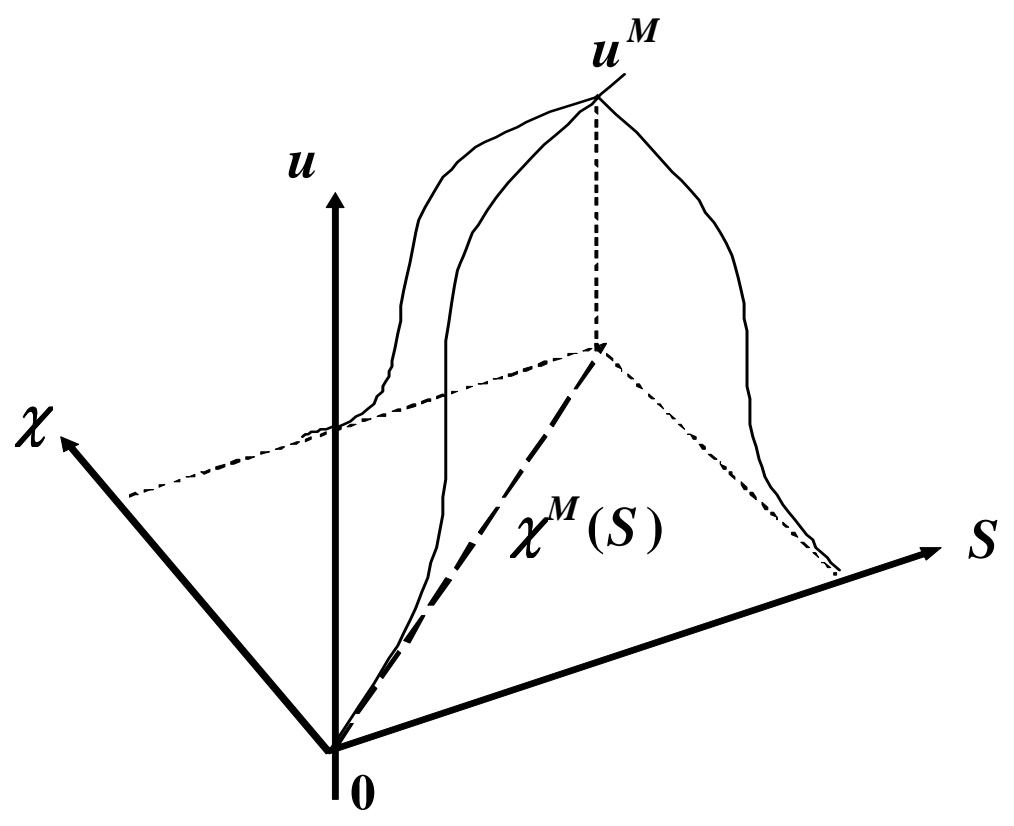

Figure 1: 


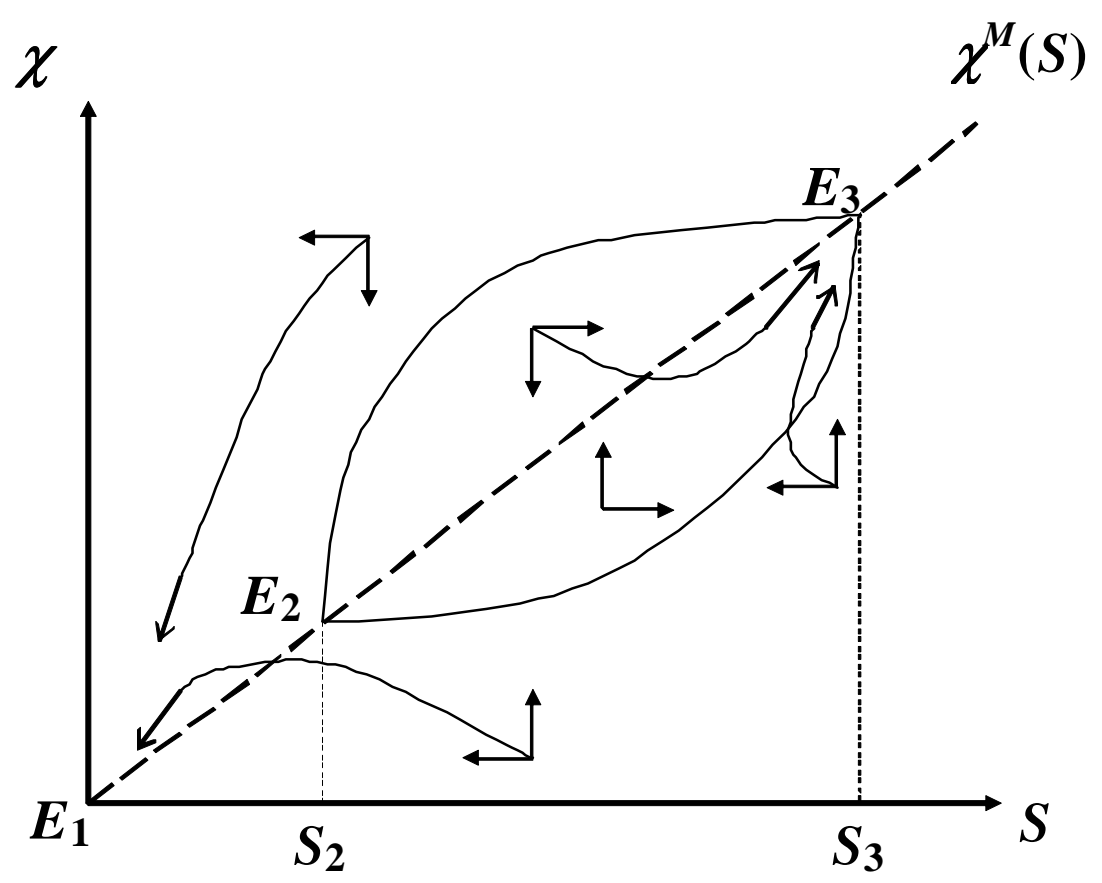

Figure 2: 